\title{
Integração, exclusão e solidariedade no debate contemporâneo sobre as políticas sociais
}

\author{
Integration, exclusion, and solidarity \\ in the current social policy debate
}

\footnotetext{
1 Departamento de Ciências Sociais, Escola Nacional de Saúde Pública, Fundação Oswaldo Cruz. Rua Leopoldo Bulhões 1480 Rio de Janeiro, $R J$ 21041-210, Brasil. rosana@ensp.fiocruz.br
}

\begin{abstract}
The current global trend involving transformation of work and the crisis in large government economic development and intervention projects in the market are raising new challenges for social policies to combat poverty. This study reconstitutes and analyzes the tensions, paradoxes, and main consequences of this process, focusing on problems concerned with combining solidarity strategies and public welfare systems.

Key words Poverty; Public Policy; Public Assistance
\end{abstract}

Resumo A tendência hoje global de transformação do mundo do trabalho articulada à crise dos grandes projetos de desenvolvimento econômico e de intervenção do Estado no mercado, tem trazido novos desafios para as políticas sociais contra a pobreza. O objetivo deste artigo é reconstituir e analisar, parcialmente, tensões, paradoxos e alguns dos principais desdobramentos deste processo, dando especial ênfase aos dilemas ligados à perspectiva de fazer interpenetrar estratégias solidárias e esquemas públicos de proteção social.

Palavras-chave Pobreza; Política Social; Assistência Pública 
"Nossa época é tudo menos um ponto final ou culminância, pouco importando quantas derrocadas parciais, como em períodos de transição estruturalmente semelhantes, possam ocorrer. Neste aspecto, também ela abunda em tensões não superadas, em processos inconclusos de integração, cuja duração e curso exato não são previsíveis" (Norbert Elias, 1993:273)

A estratégia, hegemônica até meados do século XIX, de corrigir os efeitos perversos da nova sociedade salarial sem uma intervenção significativa do Estado na economia, ou ainda, na garantia de benefícios sociais, abre caminho para profundas tensões políticas. Progressivamente, as formas habituais de equacionar a separação entre o indivíduo vítima de infortúnio - o bom indigente - e o preguiçoso ou malandro, tornam-se intensamente problemáticas. Os dispositivos contratuais, os mecanismos do mercado e as iniciativas de seguridade social experimentam, pouco a pouco, uma difícil convivência. As práticas filantrópicas, apesar de representarem um passo fundamental para o reconhecimento da pobreza como um problema coletivo, mostram-se frágeis frente às exigências de integração social.

Na verdade, como analisa Castel (1995), a história social do século XIX revelará a emergência de uma problemática radicalmente nova: a despeito do progresso e da riqueza alcançados com a dinâmica de produção capitalista industrial, surge uma "vulnerabilidade de massa”. A incerteza, a precariedade e as novas formas de instabilidade social continuam a crescer pari passu ao processo de industrialização. Ou seja, desafiando o "otimismo liberal", uma grande parcela da população é continuamente lançada na indigência. A "questão social” emerge, assim, revelando a miséria não como algo acidental mas como uma face da civilização moderna industrial.

Desta forma, enquanto um fenômeno multifacetado, o pauperismo do século XIX ilumina, de maneira contundente, os problemas postos pela ruptura das formas de produção familiar, pela precariedade das novas ocupações, pela baixa qualificação dos trabalhadores e pela destituição relativa. No processo de emergência da sociedade industrial, a aquisição de novos gostos, desejos e necessidades e, ao mesmo tempo, a incapacidade de satisfazê-las, criará paradoxalmente, situações de pobreza mais dramáticas em países como a Inglaterra do que em regiões menos desenvolvidas da Europa, como Portugal.

Esta é a perspicaz observação de Tocqueville (1985) sobre os paradoxos do progresso industrial que desmantela formas de organização tradicionais e protetoras sem ainda ofere- cer nada em troca. Neste sentido, ultrapassando a dimensão puramente econômica, o processo de pauperização da população tornará evidente a crise das formas de inserção social. Situações de equilíbrio entre condições de trabalho e redes de proteção social são dissolvidas e as medidas centradas em uma "política social sem Estado" e em um "sistema de regulações morais”, pouco a pouco, mostram-se ineficazes frente aos novos estados de privação.

Assim, ainda que uma vasta rede de corporações, sociedades de ajuda mútua e associações de amparo à pobreza, estruturadas sob a lógica da adesão facultativa, tenham sido criadas ao final do século XVIII e século XIX, como por exemplo as chamadas friendly societies na Inglaterra, a manutenção de mecanismos contratuais de cotização como principal forma de financiamento e controle das ações, torna-se uma solução precária. Os baixos rendimentos e a ampliação do espectro de carências sociais inviabiliza, progressivamente, a manutenção do sistema de contribuições voluntárias. Como aponta Rosanvallon (1995), desafiando as esperanças contidas no processo de industrialização, os trabalhadores, ou os indivíduos "independentes e previdentes" vêem-se, efetivamente, destituídos das condições mínimas de sobrevivência. Este processo, como sinaliza o autor, trará uma profunda perplexidade ao pensamento liberal: "Se o indigente é um indivíduo, o pauperismo é um fato social massivo, dominante na classe operária : ele representa a chegada de um novo tipo de situação social, a do proletariado. Situação social esta que não pode ser tratada através da lógica simples da assistência, mas que impõe o redimensionamento dos próprios fundamentos da organização da sociedade..." (Rosanvallon, 1995:22).

O dilema da "obrigação à previdência", ou seja, da introdução da obrigatoriedade na captação das contribuições e, também, da seletividade na distribuição dos benefícios, torna-se inescapável. Embora ferindo os princípios da liberdade e da responsabilização individuais ligados ao ideário liberal, tais alternativas entram na pauta das políticas de proteção aos pobres. Com efeito, o final do século XIX testemunha uma verdadeira reviravolta em torno das ações contra pobreza e a vulnerabilidade social. O surgimento de interpretações não liberais desta problemática contribui para a emergência de novos campos de interação entre as noções de direito e dever e, também, de novas racionalidades acerca das relações entre as questões morais e sociais ligadas à pobreza.

Assim a despeito dos fracassos no que se refere à mudanças políticas efetivas o movimen- 
to cartista na Inglaterra, por exemplo, não só irá colocar a pobreza no centro da atenção pública, como também, irá buscar redefinir o perfil das demandas populares. Como afirma Himmelfarb (1988), a falta de direitos políticos compartilhada pela maioria da população, para além das privações materiais, no ideário cartista, irá definir a condição de pobre: "Os cartistas tinham a tarefa de politizar os pobres, não para radicalizá-los e torná-los ativistas, nem tão pouco para torná-los uma força política reconhecida, mas para outorgar-lhes as mais altas qualidades dos seres humanos, as qualidades que os fazem verdadeira e plenamente humanos em um sentido clássico: animais políticos, gente nascida para ter cidadania" (Himmelfarb, 1988:313).

Ao mesmo tempo, o surgimento de uma doutrina solidarista ao final do século XIX e, conseqüentemente, a busca de novas regras de justiça social, terá profundo impacto no desenho das políticas sociais. Tributária do debate sobre as novas formas de coesão social e vinculação comunitária que mobilizaram Auguste Comte e Pierre Leroux, a temática da solidariedade, irá favorecer a transformação das formas de intervenção pública em torno da miséria e da destituição, traduzindo uma nova concepção de pertencimento social. Assim, significando "uma certa representação do laço social", o solidarismo irá provocar o surgimento de uma alternativa à regra de justiça liberal.

Como aponta Jacques Chevallier (1992), ainda que seja mantida a perspectiva contratual, na doutrina solidarista o contrato de associação entre os indivíduos parte da idéia de uma interdependência "natural" que, uma vez rompida, põe em xeque a própria possibilidade de manter um corpo social estável. Assim, embora o princípio de solidariedade, tal como formulado ao final do século XIX, implique em que cada um deva arcar com os riscos da existência é fundamental, por outro lado, a participação de todos na garantia do bem estar. O Estado, neste aspecto, adquire um papel menos residual e acessório, tornando-se responsável pela materialização da solidariedade através de mecanismos e estratégias próprios de repartição dos bens e serviços sociais.

Para Ewald (1996), as leis francesas regulamentando a assistência médica gratuita aos indigentes (1893), a indenização por acidentes de trabalho (1898), a assistência aos idosos e inválidos (1905) e outras iniciativas no campo da proteção social, serão alguns importantes desdobramentos da doutrina solidarista. Na Inglaterra, a promulgação do Old Age Pensions Act em 1908 também revela a emergência de um novo amálgama entre direitos, deveres e justiça social no âmbito do ideário liberal. Ainda que de imediato, a velha categoria de "indigente meritório" permaneça orientando a seleção de beneficiários, a perspectiva de responsabilização individual pelo bem-estar é transformada. Nas palavras de Rosanvallon (1995), o novo perfil da proteção social gestado ao final do século XIX e início do século XX, irá configurar "uma via para as políticas sociais que não necessitará recorrer à uma problemática de natureza jurídica e moral e, permitirá aos liberais construir um sistema de seguridade capaz de bloquear o espectro do socialismo" (Rosanvallon, 1995:25).

A noção de risco, a qual irá fornecer uma "dimensão probabilística do social", unificando os problemas da velhice, do desemprego e da doença enquanto problemas que tendem a afetar os homens de uma forma previsível e controlável, expandirá a problemática do direito à assistência. Embora o direito ao bem-estar permaneça, até meados do século XX, principalmente voltado ao trabalhador sob risco, a solidariedade, mesmo sob esta concepção contratualista, irá tornar-se uma "referência incontornável" e "fio condutor indispensável à construção e conceitualização das políticas sociais" (Chevallier, 1992:7).

Assim, o pauperismo, bem como o surgimento de novas matrizes ideológicas e atores sociais, transformam o paradigma da previdência individual como principal mecanismo de enfrentamento da miséria. Como analisa Castel (1995), o liberalismo utópico do século XVIII, preocupado em retirar os obstáculos postos à liberdade, sofre, neste sentido, um importante deslocamento. Se antes, como ressalta o autor, o alvo da luta dos liberais era a destruição das regulações sociais arcaicas e do antigo sistema de privilégios, ao final do século XIX a questão a ser enfrentada será a do risco de dissolução do tecido social.

Por outro lado, nesta trajetória, as interpretações maximalistas da solidariedade em direção à consolidação de um direito à assistência ligada à cidadania e não à condição de trabalhador, também serão traduzidas em novas perspectivas para as políticas de combate à pobreza e à vulnerabilidade social. A engenharia de "indenização" montada a partir dos recursos advindos do trabalho será alvo de críticas e de oposições. Diferentes "arranjos de proteção social” serão criados em cada sociedade, a partir de configurações políticas, econômicas e culturais determinadas. Assim, como no processo de irrupção do pauperismo no século XIX, irão surgir novos limites e dilemas em re- 
lação ao formato das ações contra a miséria e aos critérios para a determinação dos benefícios sociais.

Neste sentido, o século XX irá se deparar, tanto com o desafio de construir sistemas redistributivos capazes de impedir o crescimento das desigualdades, em um contexto de generalização do mercado, como também com os riscos de desagregação da solidariedade social. O problema da restauração de vínculos sociais, dos laços de interdependência e da solidariedade entre os indivíduos que marca o percurso da modernidade, neste aspecto, permanecerá atual.

\section{As políticas públicas contra a pobreza no século $X X$ : 0 direito à proteção}

Como vimos anteriormente, uma vez deslocado o eixo da intervenção pública contra a pobreza da noção de responsabilidade individual para uma um tipo de solidariedade contratual baseada na idéia de risco, tanto a participação dos indivíduos como a intervenção do Estado são transformadas. Aos poucos, a solidariedade inicialmente horizontal representada, por exemplo, pela assistência aos desempregados e aposentados a partir da contribuição dos trabalhadores ativos, amplia-se em direção à nova lógica da solidariedade "nacional". Ou seja as relações lineares entre a cotização e o acesso aos benefícios são desdobrados em novas formas de financiamento aos quais, em última análise, levam o sistema de proteção social a formatos menos residuais e mais universalistas.

Como analisa Kornis (1994:37), "a desvinculação dos benefícios face aos salários, o estabelecimento de um sistema financeiro repartitivo e não cumulativo e, também, a contribuição compulsória e universal baseada nos salários e nos tributos", possibilita a expansão das políticas sociais. Sem dúvida, a introdução dos dispositivos macroeconômicos preconizados pelo ideário Keynesiano em vários países capitalistas industriais europeus, possibilitaram a garantia, não só da mobilidade da força de trabalho, como também da estabilidade da produção e dos níveis de consumo da população.

Ao mesmo tempo, através de bases não necessariamente contributivas, os benefícios sociais foram generalizados de tal forma que a assistência seletiva tradicional, em várias sociedades européias, pôde ser rompida em direção à construção dos chamados welfare states. Neste sentido, o investimento na educação da população, na ampliação do consumo e na compensação de riscos ligados ao trabalho deixou de ser regido pela lógica bilateral do mercado.
No entanto, para além do impacto das transformações econômicas, a emergência de uma nova formulação em torno das idéias de cidadania e direitos sociais teve papel decisivo na construção do Estado-previdência. O consenso em torno das relações entre proteção e direitos do cidadão, expressas no conjunto de reformas sociais ocorrido na Inglaterra após a II Guerra Mundial, alcança a maioria dos países socialdemocratas. A clássica formulação de Marshall, feita em 1949 (Marshall, 1967), acerca do componente social da cidadania, sintetiza a nova perspectiva assumida pelas políticas públicas. A tensão histórica entre a afirmação do direito natural, instituinte da visão moderna da sociedade composta por indivíduos livres e iguais e, o direito positivo, ou seja, o acesso à representação política e à igualdade social é, portanto, equacionada através de um novo pacto. Um amplo espectro de ações públicas são assim implementadas, rompendo as fronteiras da atenção pública restrita e estigmatizante da New Poor Law, em direção ao desenvolvimento de iniciativas mais amplas e voltadas à melhoria das condições de habitação, saúde, ocupação e bem estar em geral.

Cabe aqui ressaltar, porém, que apesar de uma certa "vocação universalista" o welfare state assumirá diferentes contornos em cada contexto social. Sem representar um sistema neutro de repartição dos riscos e infortúnios da vida, o desenvolvimento das redes de proteção social na segunda metade deste século irá depender de como o problema da pobreza e da vulnerabilidade social será processado em cada arena política. Nas palavras de Bobbio (1992:77), "o campo dos direitos do homem - ou, mais precisamente, das normas que declaram, reconhecem, definem, atribuem direitos ao homem aparece, certamente, como aquele onde é maior a defasagem entre a posição de norma e sua efetiva aplicação. E essa defasagem é ainda mais intensa precisamente no campo dos direitos sociais".

Como aponta Baldwin (1990), embora os países mais industrializados e com história de fortes movimentos operários apresentem uma tendência maior à construção de estruturas de bem estar, muitas vezes não é possível estabelecer, de maneira linear e uniforme, correlações deste tipo. Para o autor, a dificuldade da "abordagem trabalhista operária” será, neste sentido, formular uma explicação consistente sobre o crescimento do welfare state em nações com pouca presença política da social-democracia ou, ainda, sobre a extrema variação nos perfis de proteção pública em países com semelhantes níveis de mobilização dos trabalhadores. Assim em geral, embora a classe operá- 
ria seja o grupo mais interessado na consolidação do Estado-previdência, a análise das diferentes experiências de política social mostrará uma maior pluralidade em torno dos atores relevantes no âmbito do processo redistributivo.

Ao mesmo tempo, o próprio significado da cidadania é, muitas vezes, desdobrado e traduzido a partir das crenças, valores e paradigmas compartilhados nas relações sociais. Nos Estados Unidos, por exemplo, as reformas sociais ligadas à questão da miséria e da pobreza, em geral, tendem a não ultrapassar o conteúdo moral da noção de "pobre meritório" ou undeserving poor. Neste aspecto, a responsabilização individual quanto à pobreza e a preocupação em classificar os pobres atravessa a estrutura institucional de bem estar, resgatando, portanto, um discurso moralizante sobre os pobres. Como analisa Katz (1989), mesmo o crescimento dos níveis de destituição e miséria em diversos períodos da história social e econômica americana, não abalaram a definição moralizante da pobreza. A Grande Depressão de 1929 e os altos níveis de desemprego que marcaram o período, neste sentido, tiveram pouco impacto na visão da ajuda pública como algo pejorativo.

A demanda por benefícios públicos para minorar os efeitos da pobreza e da fragilidade social, em geral, tende a repercutir nesta sociedade como um sinal de fracasso individual. É o que assinala Katz (1989:86): "Com efeito, os pobres evocam duas imagens distintas entre os americanos bem sucedidos. Quando eles tornam-se visivelmente patéticos, eles são os homeless; quando eles parecem ameaçadores, eles tornam-se os underclass. Embora estes grupos se sobreponham, o discurso público implicitamente classifica-os a partir do grau de responsabilidade por sua situação. Na medida em que eles permanecem suplicando ajuda e não militando politicamente, sendo objeto de caridade menos que sujeitos de protesto, os homeless tornam-se the new deserving poor".

Os esforços para garantir o acesso à políticas de bem estar enquanto exercício de um direito social, reduzindo o estigma e impondo novas perspectivas legais para os pobres na sociedade americana estão, desta forma, presos à possibilidade de uma nova descrição cultural. Sem dúvida, outros aspectos são de extrema relevância para a caracterização do perfil de solidariedade social que orienta as redes de proteção social nos Estados Unidos. No entanto, tal aproximação extrapola o objetivo do debate aqui desenvolvido. Na verdade, a idéia é reter uma imagem menos instrumental e racionalizada dos inúmeros desdobramentos do Estado-previdência no século XX.
Neste aspecto, as análises economicistas calcadas na relação entre custo e benefício, ou ainda, as interpretações presas à idéia de uma "natureza humana essencial" capaz de definir os rumos das políticas sociais, são ambas inconsistentes. Na maioria das vezes, as reações em torno das políticas voltadas à pobreza dependem das preferências valorativas dos indivíduos e também, da própria capacidade da intervenção pública transformar direta ou indiretamente estas preferências. Com isso, o processo de construção de políticas voltadas à pobreza e à vulnerabilidade social é extremamente dinâmico. Como indica Hirschman (1984:10) "os mesmos valores que servem bem a uma sociedade em uma fase - a crença no valor supremo da individualidade, a insistência na realização e na responsabilidade individuais - poderão ser um obstáculo mais tarde, quando um ethos comunitário e solidário se fizer necessário".

Neste sentido, é correto afirmar que o pósguerra tende a deslanchar um movimento profundo de renovação das iniciativas no campo das políticas sociais. Os direitos sociais, de acordo com os valores compartilhados em cada cultura, tornam-se um tema privilegiado na agenda estatal. Ou seja, emerge um novo compromisso político em torno do bem estar e o componente social da cidadania articula-se às dimensões civil e política, produzindo um argumento a favor de sistemas de proteção social mais abrangentes. Sem dúvida, como aponta Bodstein (1995) este processo está ligado à trajetória de fortalecimento democrático e ampliação do espaço público, onde surgem novas identidades políticas e sujeitos sociais capazes de propor alternativas no tratamento da questão social.

No entanto, este percurso não será homogêneo, consensual ou linear. Se a pactação de um novo projeto de bem estar é favorável a formatos universalizantes, isto não significa dizer que valores, interesses e perspectivas divergentes são anulados. Na verdade, o acordo em torno das concepções de bem estar, das estratégias redistributivas ou das modalidades de ação pública contra a miséria será permanentemente redefinido ao longo do tempo.

Sob este aspecto, os processos de globalização econômica e de transformação do mundo do trabalho, iniciados nos anos 70, e que culminam nos anos 80 e 90, provocam a necessidade de mudanças nas orientações relativas aos padrões de financiamento e gestão do Estado. A ruptura da estabilidade e da "soberania econômica” de um número cada vez maior de estados nacionais desdobra-se numa perda importante de autonomia na condução das po- 
líticas sociais. Ao mesmo tempo, a idéia de que a generalização da ação pública contra a pobreza alimenta uma conduta de vida "hedonista e parasita" (Offe, 1984) é reinscrita no debate acerca da crise dos Estados de Bem Estar.

Em última análise, o ideal do pleno emprego, o "paradigma previdenciário" em que os problemas sociais são remetidos à perspectiva controlável do risco, e mesmo a idéia de direito social, perdem força frente aos impasses vividos pelas sociedades industriais contemporâneas. Desse modo, uma profunda crise social, política e econômica começa a abalar os alicerces das ações públicas contra a pobreza construídos nos anos 50. Uma nova paisagem social combinando transformações tecnológicas e a emergência de novas formas de privação combinadas às antigas, impõe, assim, uma revisão dos argumentos e esquemas explicativos ligados ao tema das políticas sociais. Assim, se nos anos 50, como salienta Dahrendorf (1992), a batalha por desvincular o status cívico, político e social da posição econômica parece equacionada, criando-se um patamar comum de prerrogativas enquanto base para o acesso ao bem estar, na maioria das democracias modernas após os anos 70, este arranjo começa a se tornar insatisfatório.

\section{Os limites do Estado-previdência frente à "nova questão social"}

Até os anos 70, pode-se dizer que o Estado de Bem Estar nas sociedades desenvolvidas, dá uma resposta satisfatória às questões da vulnerabilidade social e da destituição. Em um horizonte moldado pala perspectiva do pleno emprego e crescimento econômico, a "técnica previdenciária" voltada a abrandar os riscos de degradação social e pobreza advindos da doença, da velhice e da perda temporária da remuneração salarial, manifesta uma razoável eficácia. A "socialização dos riscos" e os mecanismos de redistribuição mostram-se, assim, estratégias capazes de solucionar o conflito em torno da integração social e o drama da miséria.

No entanto, pouco a pouco, transformações no processo produtivo e uma "rarefação dos empregos”, sobretudo os de baixa qualificação, produzem um amplo contingente de desempregados e novos dilemas para a intervenção pública. Sem pretender realizar uma análise exaustiva deste processo, é importante sinalizar que a forma de solidariedade baseada, principalmente, na relação entre contribuição e prestação de serviços ou acesso a benefícios, deixa de ser capaz de contornar a diversidade de situações de precariedade e fragilidade sociais advindas do surgimento de novas desigualdades e riscos.

Por um lado, como aponta Castel (1995) o desemprego estrutural ou de "longa duração" causa um forte desequilíbrio entre os trabalhadores e os beneficiários da proteção pública. De outro lado, para além do fim do pleno emprego e da crise de financiamento da seguridade social, há um deslocamento em torno do papel do trabalho como principal agente de integração social. Fenômenos tais como a desestabilização das classes trabalhadoras e assalariadas em geral, precarização das formas de ocupação e alternância entre atividade e nãoatividade, são combinados ao aparecimento de grupos "não-integráveis" ao processo produtivo. Assim, a imagem da pobreza como uma situação residual é transformada e multiplicamse diferentes processos de desqualificação social, impossíveis de serem compreendidos à luz de uma abordagem economicista e estanque.

Ao mesmo tempo, o welfare state, tido como principal condutor do progresso e responsável pela coesão social, torna-se incapaz de recriar laços de solidariedade. As "formas burocratizadas e impessoais" de gestão, presas à uma lógica distinta da que preside a vida comunitária ou a participação em redes de sociabilidade mais amplas, aos poucos perde sua capacidade de resolução frente aos novos dilemas sociais. Ou seja, embora a proteção social e uma nova concepção de solidariedade tenham sido construídas concomitantemente, a maneira como esta "seguridade" foi implementada contribuiu para a redução do engajamento dos indivíduos nas ações públicas.

A redistribuição "automatizada" de benefícios sociais criou, desta forma, um coletivo abstrato, onde os grupos sociais foram "destituídos de suas responsabilidades” em relação ao destino de seus membros. A interdependência que caracteriza a vida social, neste aspecto, foi sendo progressivamente neutralizada ou mesmo desfeita, como aponta Himmelfarb (1995: 245): "Após realizar uma grandiosa tentativa de objetivar o problema da pobreza, vê-lo como produto de forças econômicas e sociais impessoais e concretizado o esforço de distinguir as políticas sociais como esferas desmercantilizadas, nós descobrimos que estas políticas põem em perigo tanto a moral como o bem estar material de seus beneficiários. Na política social 'desmoralizada', ou seja, separada de qualquer critério moral, contrapartida ou expectativa, nós desmoralizamos tanto os indivíduos que recebem a assistência como a sociedade como um todo". 


\section{O advento do "paradigma" da exclusão}

Na tentativa de compreender as singularidades das situações de incerteza e precariedade social contemporâneas, muitos autores têm recuperado a noção de exclusão, cara ao pensamento social influenciado pela Antropologia Estrututural, tal como sugere Zaluar (1997). O termo ganha maior penetração nas Ciências Sociais, a partir do livro de René Lenoir, Les Exclus, publicado em 1974. Preocupado em caracterizar os grupos "inadaptados" socialmente, Lenoir (1974) busca discutir no contexto das sociedades industriais e urbanizadas contemporâneas a situação dos indivíduos que, em virtude de alguma enfermidade física ou mental, falta de formação adequada ou determinado comportamento, são incapazes de suprir suas necessidades, tornando-se mesmo um perigo para si mesmos e para o restante da coletividade.

Para Paugam (1996), o principal mérito do livro, escrito segundo ele, não por um grande teórico mas por um autor sensível às questões sociais, é o de suscitar e ampliar um debate. Diferentemente da visão "individualizante" da pobreza e exageradamente otimista do desenvolvimenro econômico e social, a abordagem de Lenoir leva a uma reflexão sobre os conflitos ligados à experiência de vida nas sociedades industriais modernas. A urbanização desordenada, os vários tipos de segregação social, a violência generalizada, a desigualdade econômica e a inadaptação escolar e profissional, tornam-se, assim, elementos chave para o entendimento do fenômeno da exclusão. No entanto, a dificuldade em avançar na caracterização dos diferentes processos e trajetórias de desqualificação social, ou ainda a presença de um certo determinismo em torno da questão da "adaptação social”, irão limitar o alcance heurístico desta abordagem.

Assim o termo irá reaparecer no debate sobre pobreza somente após os anos 80. Em parte, isto se deve ao aumento do desemprego e ao surgimento de um quadro complexo, não redutível, por exemplo, aos processos de expropriação da classe trabalhadora ou à segregação espacial. O sucesso da idéia de exclusão após os anos 80, está relacionado a um quadro de ruptura dos laços sociais combinado ao enfraquecimento das formas de coesão e solidariedade habituais. O crescimento do isolamento social, a deterioração das formas de convivência, o fracasso das iniciativas de participação coletiva e, sobretudo, a incerteza generalizada frente aos rumos das políticas sociais, constróem, desta forma, um terreno fértil para a emergência de um verdadeiro "paradigma" da exclusão.
Diferentemente do contexto do pauperismo no século XIX, segundo Castel (1995), os pobres e destituídos, hoje, não podem mais ser considerados segmentos explorados ou mesmo marginais. Apesar dos novos grupos de destituídos viverem a impossibilidade de organizar um lugar estável na estrutura de emprego dominante e, também, nos modos de vinculação comunitária tal qual os vagabundos e "paupers", as experiências de vulnerabilidade social perderam um sentido comum. Ou seja, a expulsão do emprego, a precariedade da proteção pública e o isolamento social, adquirem uma inteligibilidade distinta da vivida antes do surgimento dos Estados de Bem Estar e, também, da perspectiva de plena estabilidade e crescimento econômico do pós-guerra. Por outro lado, transformam-se as relações entre Estado e cidadania. Na verdade, atravessados por forças contraditórias como a explosão de múltiplas identidades, as quais tendem a reforçar solidariedades particulares e, por movimentos de integração e relações de interdependência, os sentimentos de pertencimento à nação e a própria natureza da construção política do cidadão, sofrem metamorfoses. Principalmente na Europa Ocidental, o grande número de imigrantes, trazidos no bojo do movimento de formação de uma "rede global de circulação de mão-de-obra" (Wacquant,1994:19), vivendo sob condições de trabalho informais e, muitas vezes, degradantes, revigora o debate acerca dos dilemas do processo de integração social.

O fenômeno de dissolução da nação tradicional produz, assim, novas interrogações acerca das questões da cidadania e do welfare state. Como analisa Schnapper (1996), ainda que as sociedades plurais, no âmbito do projeto democrático moderno, busquem garantir a igualdade política a todos os cidadãos e a igualdade cívica a todos os seus membros (estrangeiros ou não), surgem, permanentemente, tensões relativas à questão do pertencimento a uma mesma "comunidade de destino". Assim, são exigidas novas formas de articular o domínio do político, do jurídico e também das diferentes referências culturais para além do modelo de cidadania definido apenas pela relação do indivíduo com o Estado-nação.

Desta forma, a idéia de exclusão torna-se quase um lugar-comum nas análises sobre os problemas sociais contemporâneos. Para alguns autores, esta generalização e, mesmo, banalização do uso da noção de exclusão é responsável por um tratamento inadequado das múltiplas dimensões da chamada "nova questão social". A tendência a omitir tanto a dinâmica como a heterogeneidade das situações vi- 
vidas pelos grupos desfavorecidos, acaba perdendo de vista universos específicos e singulares. A autonomização das situações de precariedade e a configuração de sociedades duais, polarizadas entre incluídos e excluídos, são marcos teórico-metodológicos impróprios para caracterizar a questão social contemporânea.

Assim, para além do lugar ocupado na divisão social do trabalho, importa pensar também a participação dos indivíduos em redes de sociabilidade e sistemas de proteção social. Neste aspecto, faz-se necessário um approach que permita perceber a existência tanto de posições intermediárias, quanto de trajetórias alternadas de integração e exclusão. Desta forma, como sugere Castel (1995), o conceito de desafiliação, ao invés de exclusão, permite uma leitura multidimensional e dinâmica das novas formas de instabilidade social. Se as situações de precariedade não se resumem à posições extremas e estanques e, por outro lado, os excluídos não são uma categoria social específica, é importante buscar conceitos e noções capazes de situar os desafios da sociedade contemporânea em outros termos.

Nesta perspectiva crítica Diddier (1996), afirma que o vocabulário da exclusão, pode dificultar a identificação dos sujeitos e agentes responsáveis pelas situações de precariedade e fragilidade sociais. As desigualdades são percebidas de forma monolítica, e as trajetórias diversas em que os indivíduos transitam da integração à acumulação de fracassos e demandas insatisfeitas, são relegadas a segundo plano. Com isso, as origens e causas da exclusão são insuficientemente exploradas. Ao mesmo tempo, a idéia de exclusão que divide o mundo em dois estados, inviabiliza a investigação das relações e dos elos de ligação existentes entre os grupos sociais: "Não há um mundo de pessoas felizes e outro de miseráveis (....) a exclusão caracteriza estes dois mundos como espaços, mas os sujeitos que ocupam estes espaços não são qualificados, a sua presença em cada um destes domínios parece acidental" (Diddier, 1996:26).

Apesar destas considerações porém, mesmo dentre os autores que ressaltam os problemas ligados ao "paradigma da exclusão", há um certo consenso em relação à necessidade de explorar também suas potencialidades. Na verdade, o debate em torno da exclusão, recupera a interrogação sociológica, que acompanhou as obras de Comte, Durkheim e Weber, acerca de como manter os laços sociais nas sociedades fundadas sob o princípio da soberania individual. Neste aspecto, se existem riscos, há também a possibilidade de construir uma reflexão crítica consistente sobre a crise social da atua- lidade. Assim, se não podemos falar de exclusão como um estado absoluto - "exclusion de quoi?" - existe uma dialética de exclusão e inclusão: "Toda organização social, qualquer que seja o seu nível - da família à empresa ou à nação - implica, por definição, a inclusão de uns e a exclusão de outros. O que importa estudar não é tanto a exclusão em si, mas as suas formas específicas, derivadas de processos de exclusão $e$ inclusão" (Schnapper,1996:23).

Deste ponto de vista, é possível empreender uma análise acerca das populações fragilizadas, que apresentam maiores chances de ruptura dos vínculos profissionais, familiares e relacionais, sem omitir os elementos de ligação e também de afastamento entre as diferentes trajetórias. Sem dúvida, os elos que garantem a inscrição dos indivíduos nas redes de sociabilidade, tais como a família, o trabalho ou as instituições de proteção social, apresentam interdependências. Mas como ressalta Paugam (1996), no estudo dos processos de desqualificação social contemporâneos, a questão central é analisar o perfil das desigualdades como algo em permanente movimento. Ainda que, concretamente, existam segmentos populacionais que tendam a acumular incapacidades, perdas e fracassos e, de outro lado, grupos privilegiados e com acesso ilimitado a bens e serviços sociais, é possível perceber também, indeterminação e imprevisibilidade no acompanhamento longitudinal dos percursos individuais.

Neste sentido, se a exclusão implica em uma revisão das políticas sociais em direção à garantia de emprego, escola, segurança pública, condições de saúde e habitação satisfatórias em um contexto de crise da sociedade salarial, também revigora a necessidade de criar e manter mecanismos de integração social singulares. Além disso, o reconhecimento de uma pluralidade de situações de precariedade no bojo do "horizonte social da exclusão", traz para a agenda das instituições de proteção social o desafio de elaborar novos compromissos e pactos que envolvam, para além das estratégias de descentralização de decisões, a construção de parcerias e relações mais estreitas com associações civis e comunitárias. Beneficiários, profissionais, e voluntários tendem a assumir, assim novos papéis.

Na nova concepção de solidariedade o que está em jogo é a participação em uma problemática que a todos diz respeito. Sem uma oposição ao Estado, mas buscando uma participação capaz de criar laços efetivos de solidariedade que a ação estatal foi incapaz de manter, a perspectiva é possibilitar novas formas de organização e exercício de pressão política em 
direção à ampliação de investimentos sociais. Essa participação é, neste aspecto, caracterizada pela descentralização e pela independência em relação ao Estado, embora dirigida a ele e com ele em permanente contato.

\section{Novos critérios e compromissos para as políticas públicas: redefinindo a cidadania e a solidariedade}

Para Rosanvallon (1995), frente à pobreza atual, a concepção tradicional de direitos sociais torna-se inoperante. Em um contexto de desemprego crescente e intensa diferenciação das trajetórias sociais, a perspectiva de intervenção do Estado através da distribuição mecânica de benefícios aos portadores de "direito" ou, ainda, de indenização nos casos de "disfunções passageiras", como a doença ou o desemprego de curta duração, perde eficácia. Desta forma, uma nova visão da proteção social, não restrita a uma "técnica de seguridade" mas, ao contrário, ligada a uma versão ampliada do modo de produção da solidariedade social, constitui-se a saída para enfrentar os problemas sociais contemporâneos. Em outras palavras, o engajamento pessoal dos beneficiários, a combinação entre indenização e inserção social e a possibilidade de articular direito e contrato na condução das políticas contra a pobreza - incorporando, assim, a idéia de contrapartida - tornam-se exigências incontornáveis.

Polemizando com a visão clássica de Rawls (1997), Rosanvallon reitera a importância de incorporar as diferenças e heterogeneidades das condições de privação na definição de políticas de bem estar. Contra a burocratização e a perspectiva tecnicista da seguridade, Rosanvallon propõe novas formas de ação que instituam um "dever individual face a pessoas particulares" (Rosanvallon, 1995:60). Novas alianças visando o combate à exclusão, a mobilização de todos e engajamento de cada um, entram em cena. A solidariedade que, como vimos anteriormente, marca a emergência das redes de proteção pública sofre, neste sentido, um deslocamento importante.

Para Donzelot (1995), a redução dos grandes antagonismos ideológicos, a crise de representação e o declínio da militância vão levar a uma reflexão menos polarizada acerca das tendências de desafiliação das categorias sociais. Sem significar a perda da dimensão política, o equacionamento da questão social hoje impõe, assim, o encontro de novas mediações e canais institucionais de negociação. Em contextos sociais de extrema complexidade e diversidade de situações, valores e demandas, embora o Estado seja ainda um elemento chave para a definição de políticas de reinserção social, é fundamental fazer interagir as dimensões pública e privada ou os espaços societários e estatais, permanentemente. "O ressurgimento do tema da solidariedade combina-se a uma inflexão de seu conteúdo. A concepção ligada à cobertura de riscos sociais é transformada (...). A noção de inserção, no lugar do direito a um benefício, passa a traduzir uma idéia ativa de solidariedade" (Chevallier,1992:132).

Assim, ainda que as questões da pobreza e da exclusão apresentem-se de forma diferenciada em países que não passaram por este processo de construção da cidadania ou de crise das políticas sociais, muitas lições podem ser aprendidas. Se nos Estados Unidos, a visão do pobre merecedor e o conteúdo moralizante da proteção social persistem, os problemas ligados à ruptura do tecido social e a necessidade de resgatar a dimensão substantiva da solidariedade, também adquirem maior relevância. Da mesma forma, se no Brasil, as intervenções estatais no combate à pobreza caracterizam-se pela timidez, precariedade e intermitência e, por outro lado, não estão assegurados os direitos sociais básicos à população pobre, a tarefa de reconstituir um perfil de convivência menos ameaçado é fundamental.

Ou seja, em países como o Brasil, onde, além do impacto do desemprego estrutural, há desagregação dos mecanismos de integração, intensas desigualdades sociais e erosão dos instrumentos necessários ao enraizamento da cidadania participativa, a busca de novas formas de intervenção pública também é crucial. No bojo de um padrão de relações e oportunidades sociais complexo, onde grandes segmentos da população vivem experiências dramáticas de penúria material e privação simbólica e, ao mesmo tempo, a ação do Estado é, muitas vezes, corrupta, inócua e incapaz de garantir a eqüidade, o debate acerca da construção de alternativas solidárias de convivência cívica mostra-se extremamente oportuno. No vazio do Estado e sem a experiência de ter os direitos sociais mais básicos assegurados à população pobre, novas formas de solidariedade tentam reconstituir o tecido social ameaçado pelo esgarçamento e fragmentação. Na verdade, nossa "questão social" embora não reflita perdas no processo de integração como nos países centrais, revela um processo que continua incompleto e ameaçado de interrupção.

As exigências de justiça confrontam-se, assim, com uma experiência de cidadania que apresenta múltiplas combinações e arranjos 
possíveis. Privilégios e particularismos afloram em uma realidade de profundas carências sociais. A falta de um entendimento público e compartilhado das regras que orientam a redistribuição dos benefícios sociais cria, permanentemente, padrões precários de sociabilidade e noções frouxas de igualdade. Neste cenário, porém, tanto o receituário liberal voltado à garantia da eficácia econômica a despeito do acirramento das desigualdades sociais, como o paradigma de intervenção estatal que orienta a defesa dos direitos adquiridos, não conseguem forjar novas saídas. Cada vez mais, as questões da pobreza e da miséria em nossa sociedade, impõem uma nova atuação do Estado e a descoberta de respostas locais e flexíveis capazes, sobretudo, de articular múltiplos atores sociais e diferentes parcerias.

Neste sentido, o debate em torno de projetos locais de desenvolvimento capazes de aglutinar experiências participativas e promover a intersetorialidade, ganha centralidade. Nesta direção, no campo da saúde, experiências auto-organizativas, institucionais e de organizações não governamentais, sinalizam um movimento complexo de redefinição de práticas e perspectivas. Tais experiências, em geral, têm sido abrigadas sob o guarda-chuva da idéia de "promoção à saúde". Obviamente, trata-se de um tema amplo e inovador, ainda que, muitas vezes, reatualize antigas proposições. Desta forma, a discussão avança tecendo acordos mas também enfatizando resistências, dúvidas e superposicões. No campo das políticas voltadas à geração de emprego e renda, a ressonância da noção de capital social, as tentativas de implementação de redes produtivas ampliadas e novas alianças entre mercado, estado e sociedade revelam, igualmente, intensas metamorfoses. Na área de educação pública, é proposto um novo "ambiente pedagógico", capaz de valorizar a autonomia e a ampliação das capacidades dos indivíduos - the capability set nos termos de Sen (1992). Pode-se dizer que, impregnado de disputas, conflitos e dificuldades, emerge um campo de possibilidades (Schutz, 1979) que pressupõe ferramentas novas e referências criativas a projetos de saúde pública, redistribuição dos benefícios sociais e bem estar. O maior desafio está, assim, em evitar o descomprometimento e assim, criar novas formas de responsabilização social e engajamento na luta contra a exclusão e a pobreza contemporâneas.

\section{Referências}

BALDWIN, P., 1990. The Politics of Social Solidarity. New York: Cambridge University Press.

BOBBIO, N., 1992. A Era dos Direitos. Rio de Janeiro: Campus.

BODSTEIN, R. C. A., 1995. Cidadania e Direitos: Dilemas da Questão Social. Tese de Doutorado, Rio de Janeiro: Escola Nacional de Saúde Pública, Fundação Oswaldo Cruz.

CASTEL, R., 1991. De l'indigence à l'exclusion, la désaffiliation: Précarieté du travail et vulnerabilité relationnelle. In: Face à l'Exclusion - Le Modèle Français (J. Donzelot, org.), pp. 137-169, Paris: Esprit.

CASTEL, R., 1995. Les Métamorphoses de la Question Sociale - Une Chronique du Salariat. Paris: Fayard.

CHEVALLIER, J., 1992. La resurgence du theme de la solidarite. In: La Solidarité: Un Sentiment Republicain? (J. Chevallier, org.), pp. 111-135, Paris: Presses Universitaires de France. 
DAHRENDORF, R., 1992. O Conflito Social Moderno. São Paulo: Zahar Editores.

DIDDIER, E., 1996. De “l'exclusion à l'exclusion”. In: L'Exclusion - Constructions, Usages, Épreuves (M.C. Lavabre, org.), pp. 5-27, Paris: Presses de Sciences.

DONZELOT, J., 1995. Face à L'Exclusion. Paris: Seuil.

ELIAS, N., 1993. O Processo Civilizador. v. 2. Rio de Janeiro: Zahar Editores.

EWALD, F., 1996. Au XIX siècle en France de la bienfaisance à la solidarité, ou la naissance de la protection sociale. In: Pauvretés (C. Brisset, org.), pp. 99-118, Paris: Hachette.

HIMMELFARB, G., 1988. La Idea de la Pobreza - Inglaterra a Princípios de la Era Industrial. México, DF: Fondo de la Cultura Económica.

HIMMELFARB, G., 1995. The De-moralization of the Society. New York: Knopf.

HIRSCHMAN, A., 1984. Getting Ahead Collectively Grassroots Experience in Latin America. New York: Pergamon Press.

KATZ, M., 1989. From the Undeserving Poor to the Culture of Poverty, the Undeserving Poor. New York: Pantheon Books.

KORNIS, G. E. M., 1994. A Crise do Estado de Bem Estar: Problemas e Perspectivas da Proteção Social. Tese de Doutorado, Rio de Janeiro: Instituto de Economia Industrial, Universidade Federal do Rio de Janeiro.
LENOIR, R., 1974. Les Exclus. Un Français sur Dix. Paris: Seuil.

MARSHALL, T. H., 1967. Cidadania, Classe Social e Status. Rio de Janeiro: Zahar Editores.

OFFE, C., 1984. Problemas Estruturais do Estado Capitalista. Rio de Janeiro: Tempo Brasileiro.

PAUGAM, S., 1996. La constitution d'un paradigme. In: L'Exclusion - L'État des Savoirs (S. Paugam, org.), pp. 7-18, Paris: La Decouverte.

ROSANVALLON, P., 1995. La Nouvelle Question Sociale. Paris: Seuil.

SCHNAPPER, D., 1996. Intégration et exclusion dans les socieéyés modernes. In: L'Exclusion-L'État des Savoirs (S. Paugam, org.), pp. 23-31, Paris: La Decouverte.

SCHUTZ, A., 1979. Fenomenologia e Relações Sociais. Rio de Janeiro: Zahar.

SEN, A., 1992. Inequality Reexamined. Cambridge: Harvard University Press.

TOCQUEVILLE, A., 1985. La Democracia en América. Madrid: Alianza Editorial.

WACQUANT, L., 1994. O retorno do recalcado - Violência urbana, raça e dualização em três sociedades avançadas. Revista Brasileira de Ciências Sociais, 24:16-30.

ZALUAR, A., 1997. Exclusão e políticas públicas: Dilemas teóricos e alternativas políticas. Revista Brasileira de Ciências Sociais, 12:29-47. 